\title{
Financial modeling of the influence of factors on the mortgage rate in developed countries
}

\author{
Mariia I. Ermilova ${ }^{1}$ \\ ${ }^{1}$ Plekhanov Russian University of Economics, Department of financial management, 117997, Moscow, Russia
}

\begin{abstract}
The article evaluates the impact of a certain list of factors on the main indicators of the development of the housing market, including its financing. Within the framework of the study, a system of statistical indicators was formed, which were divided into two blocks and their influence on each other and on the market was determined. It is essential to determine the mutual combination of housing provision and the level of GDP. According to the results of the study, a rating of the EU countries and Russia was formed in terms of housing affordability.
\end{abstract}

\section{Introduction}

At present, to form the most effective models for assessing the influence of any factors on the main indicators of financing the housing market, it is necessary to evaluate foreign experience.

Within the framework of this study, a selection of a list of data was carried out that characterizes the state of the construction industry in the European Union, as well as macroeconomic indicators.

The aim of the work is to assess the impact of socioeconomic factors on the mortgage rate in developed countries using econometric modeling.

Research objectives:

- carry out cross-country comparison of key indicators of the construction sector and factors influencing its development;

- develop a system of statistical indicators, including performance indicators and factor variables, and assess their impact on each other and the housing market;

- to determine the mutual combination of housing provision and the level of GDP per capita in the EU countries and Russia;

- to form a rating of the EU countries and Russia in terms of housing affordability.

Studies to assess the impact of various factors on the housing market were carried out to a sufficient extent by both Russian and foreign scientists.

The article "The Impact of Macroeconomic Factors and Economic Cycles on the Cost of Housing" (Ermilova, M.; Finogenova, Y., 2017) [1] analyzes how various factors can affect the development of the housing market.

Boyd T. (2014) in his study provides an analysis of the real estate market, including from the point of view of factor analysis.
Zhu B., Betzinger M., Sebastian S. (2017) [3] link the stability of the housing market with interest rates on mortgage loans.

Kokotkina T.N. (2015) [4] carries out a statistical analysis of the impact of human potential on the regional housing market.

Tatarinova L.V., Plotnikova V.A. (2018) [5] in their research assess the factors that can affect mortgage lending.

Dixie M. Blackley, James R. Follain (1991) [6] already in 1991 attempted to form an econometric model for megacities, estimated what influences the price change in different cities, what is the elasticity of supply for it.

Petr Sunega, Martin Lux, Petr Zemčík in the article "Housing Price Volatility and Econometrics" (2014) [7], on the contrary, refute econometric modeling as a way of predicting any processes. The authors point out that econometrics was unable to predict the housing price bubble and the detection of imbalances in housing markets.

Jonathan Halket, Lars Nesheim, Florian Oswald (2020) [8], using the example of Great Britain, assessed what factors can influence the choice of the population to buy or rent housing.

James R. Follain and Seth H. Giertz, in their 2012 publication [9], analyzed how econometric models can determine the growth of bubbles and declines in house prices.

Ramiro J. Rodríguez in the first part of his dissertation research on the topic "Quantitative analysis of commercial and residential real estate markets (an approach from cointegration and spatial econometrics)" forms several models for assessing the development of the housing market, using factors such as GDP per capita, percentage rates, offer of new housing, etc.

In general, it is worth noting that many econometric models were formed at an earlier date, but due to 


\section{Block I. Productive indicators (variables)}

-Z1 - Price sq. meters of an apartment in the city center, USD

-Z2 - Provision of housing, number of rooms for 1 person

-Z3 - Share of construction in GDP, \%

\section{Block II. Factor characteristics (variables)}

-U1 - GDP per capita, USD

-U2 - Cost of living index, $\%$

-U3 - Rent an apartment (1 bedroom) in the city center, USD

-U4 - Average monthly net salary (after tax), USD

-U5 - Payment for utilities (electricity, heating, cooling, water, garbage) for an apartment of $85 \mathrm{sq} . \mathrm{m}, \mathrm{USD}$

-U6 - Interest rate on mortgage in percent (annually, for 20 years with a fixed rate), $\%$

-U7 - Mortgage as a percentage of income, $\%$

Fig. 1. The system of indicators for spatial analysis of the patterns of functioning of the construction industry and entities serving the construction sector in the Eurozone and Russia.

significant changes in the global economy, constant refinements of such models were required. In this study, many aspects of the development of housing markets are considered.

\section{Methods}

To adequately assess the development of the housing market, a statistical analysis of the functioning of foreign housing markets is required. This will make it possible to determine how much the domestic market lags behind or, on the contrary, develops at a more intensive pace than foreign markets.

It is reasonable to carry out a statistical analysis of the dynamics of construction indicators in Russia and identify regional patterns simultaneously with an assessment of the markets of developed countries. This approach will reveal similar (distinctive) tendencies between the Russian Federation and developed countries, and indicate further ways of development of the Russian industry and entities that can be attributed to serving the construction industry, including here you can indicate those who produce materials for building.

Cross-country comparison of key indicators of the construction sector and factors influencing its development is required.

To conduct a study in the indicated direction, we will choose 27 members of the European Union and the Russian Federation as the compared countries. This choice is explained by the presence among them of countries with a "powerful" economy and a high standard of living of the population (for example, Germany, France, Great Britain), subjects that were part of one of the economic blocs with Russia (CMEA,
USSR), as well as outsider countries, in the position of recipients.

The process of forming a set of data characterizing the state of the construction industry in the European Union, as well as macroeconomic indicators should be based on official sources of information, such as:

1. Statistical Office of the European Union (Eurostat). - Access mode: https://ec.europa.eu/eurostat/web/main/data/database

2. Organization for Economic Cooperation and Development (OECD). - Access mode: https://stats.oecd.org/

3. UN Statistics Division. - Access mode: https://unstats.un.org/unsd/snaama/Index

4. World Bank (The World Bank). - Access mode: https://data.worldbank.org.

In addition, information on the living standards of the population of the eurozone countries was taken from the Numbeo portal. - Access mode: https://www.numbeo.com/cost-of-living/. Since the presented information sources, a system of statistical indicators was developed, consisting of two blocks (Figure 1).

For the EU countries, there is no information on the commissioning of buildings (including residential), therefore, to display the results of construction, the industry's GVA indicator was taken as a percentage of GDP. Consider the rating of the countries included in the studied population, according to this indicator (Figure 2). 


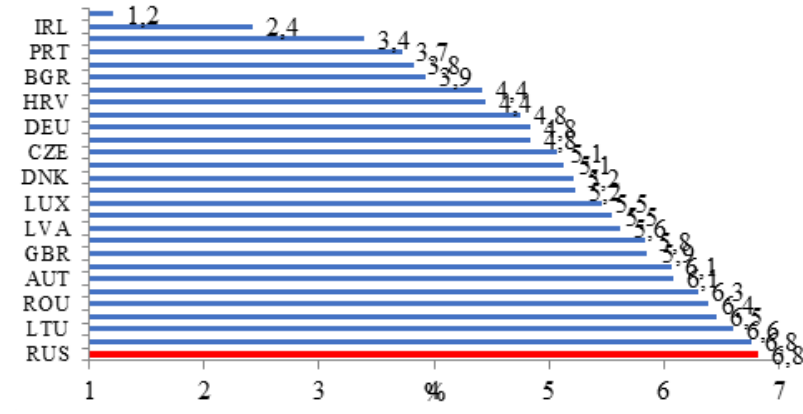

Fig. 2. Rating of the EU countries and Russia by the share of GVA construction in GDP in 2019,\% (Sources: compiled on the basis of data from the UN Statistics Division).

The information shown in the figure clearly shows that in Russia construction occupies a rather significant place in the economy, while in the more progressive EU countries the share of the industry is noticeably lower, which is explained by the existing economy. It is also worth paying attention to the minimum value of $1.2 \%$ in the case of Greece, this pattern is explained by the lack of space in the country for the construction of buildings, as well as the mild climate, which does not require significant capital investments in construction and leaves an imprint on the structure of construction costs.

A logical assumption is the idea of the difference between the EU countries in a number of indicators characterizing the housing market, which is associated with the historical state of affairs, as well as the presence of a strategic resource in a particular country. In this regard, we will consider the relationship between the indicators of block I and GDP per capita, this will allow us to establish the position of the eurozone countries and Russia relative to each other (Figure 3).

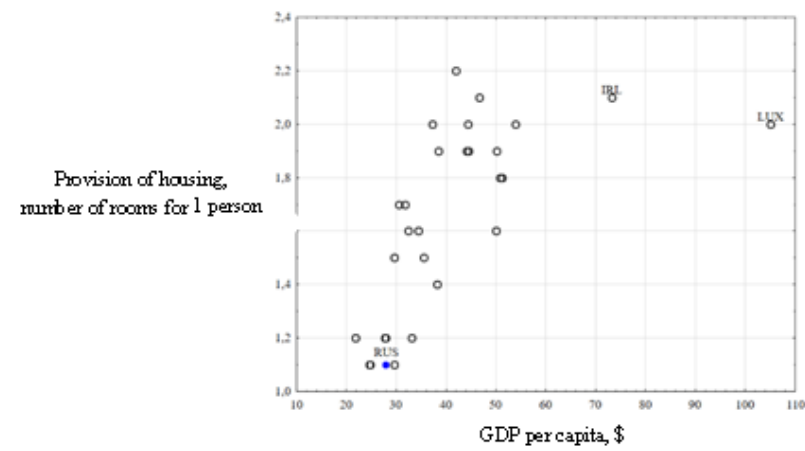

Fig. 3. Mutual combination of housing provision and GDP per capita in the EU and Russia in 2019 (Sources: based on data from Numbeo and the World Bank).

According to the information given in the figure, there is a strong direct linear relationship between the considered indicators. It is also worth pointing out the presence of two objects that go beyond the main population in terms of GDP per capita, these are IRL and LUX (countries are characterized by a high standard of living of the population). As for Russia, in terms of the combination of the indicators under consideration, the country is in the third quarter of the graph, that is, it is lagging; its closest neighbors are ROU, HRV, POL (not the most developed countries in Europe).

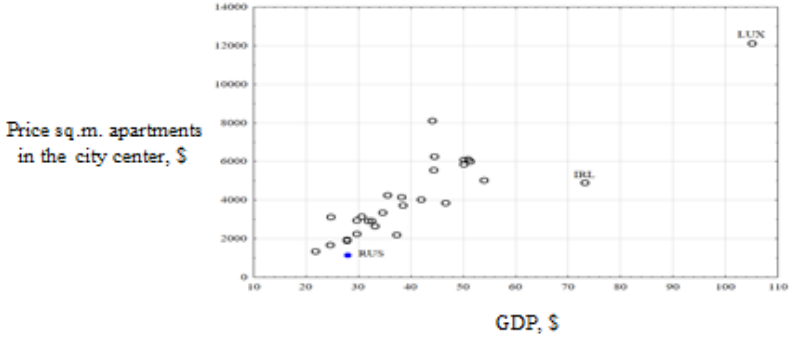

Fig. 4. Mutual combination of housing prices and GDP per capita in the EU and Russia in 2019 (Sources: compiled based on data from Numbeo and the World Bank).

If we turn to Figure 4, we see a similar picture, that is, the leadership of IRL, LUX and the lag the European countries of Russia. It is obvious that the higher standard of living of the EU population allows construction companies and other subjects of the real estate market to set high prices for housing.

\section{Results and Discussion}

Consideration of two dot diagrams allows us to formulate the following conclusion regarding Russia: firstly, despite the high rates of construction in the Russian Federation, against the background of a decreasing population, the provision of citizens with housing is significantly inferior to the level prevailing in the EU, and is at the level of outsider countries of the eurozone; secondly, the standard of living of the population of Russia is a constraining factor in the field of prices for residential real estate, which is clearly manifested against the background of developed European countries.

According to Figure 1, we have at our disposal 10 indicators characterizing construction, living standards and the real estate market, while the aggregate includes only 28 objects (countries), with such a ratio of feature space and subjects, a multidimensional grouping will not lead to a stable positioning of countries relative to each other. friend. In this regard, let us turn to such a method of multivariate statistical analysis as "multivariate scaling".

This method allows you to "compress" a multidimensional feature space to two-dimensional and place objects (in our case, countries) in a twodimensional plane. As a result, the positions of the countries participating in the analysis will become clearer, and we will be able to establish Russia's place among the members of the European Union, considering the weight of all 10 indicators.

At the first stage of the study, it is necessary to move from the initial data to the matrix of pair correlation coefficients, based on which the multidimensional scaling procedure is carried out.

At the second stage, the analysis of the positions of the countries under consideration in two-dimensional space is carried out (Figure 5).

As a result of the algorithm, the considered set of countries was divided into several clusters, on two scales. It is worth noting that the scales are abstract in 
nature, are formed based on the values of the initial variables, and do not carry any informational (including in economic terms) load but serve only to position (reference points) objects relative to each other in the Ndimensional feature space.

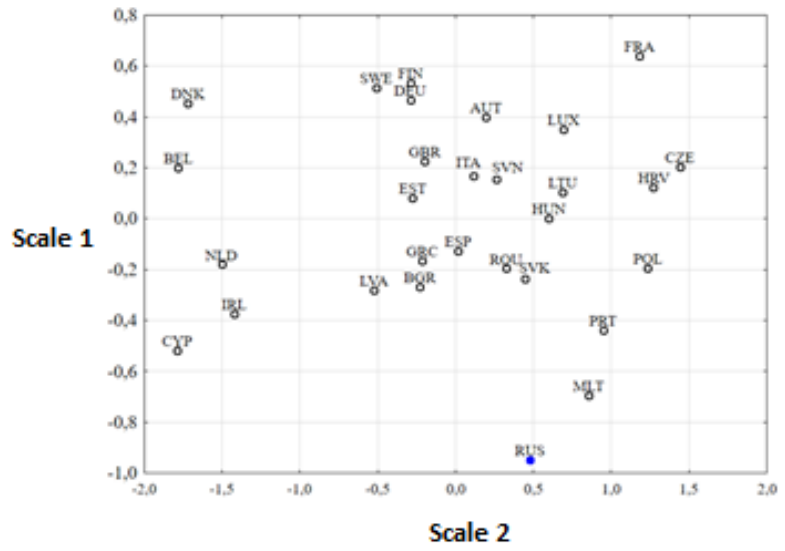

Fig. 5. Distribution of EU countries and Russia in twodimensional space.

The information shown in the figure indicates the presence of the main "clot" consisting of 23 countries (the areola of the group is outlined with a red dotted line) and a minor group of 5 subjects, as well as one object (RUS) located at the periphery of the graph. Russia is most strongly distanced from the main cluster of countries, with Malta being its closest neighbor. The current position of the Russian Federation is explained by low values for all indicators, except for U6 and U7, which characterize interest rates on mortgages and housing loans.

Thus, we can conclude that Russia lags significantly behind the European Union in terms of living standards, as a result, prices on the housing market are constrained by average per capita incomes. To illustrate the gap between the incomes of citizens and the prices of real estate purchases, we will calculate the so-called housing affordability ratio (HAC), while we will be guided by the formula:

Housing affordability ratio $=(85$ sq. $\mathrm{m} \times \mathrm{Z} 1) /(\mathrm{U} 4 \times$ 12 months $\times 3$ people).

As a result, we get the following ranking of countries in terms of housing affordability (Figure 6).

The data presented in Figure 5 indicate that the largest number of years for buying an apartment of 85 sq. m. is necessary to spend for a family of three in the Czech Republic (12.9 years), the smallest in Belgium (5.5 years), while Russia is in the middle of the rating with a value of 9.1 years. On the one hand, 6-12 years is not a significant period for the purchase of real estate, but on the other hand, the considered indicator of the housing affordability coefficient implies that all family income will be invested in the purchase of housing. The realities of life are such that no household can afford an investment of $100 \%$ of income since it is necessary to continuously maintain the standard and quality of life. In fact, the amount of cash flow directed to the purchase of housing does not exceed $30 \%$ of income, which means that the acquisition period is significantly increased.

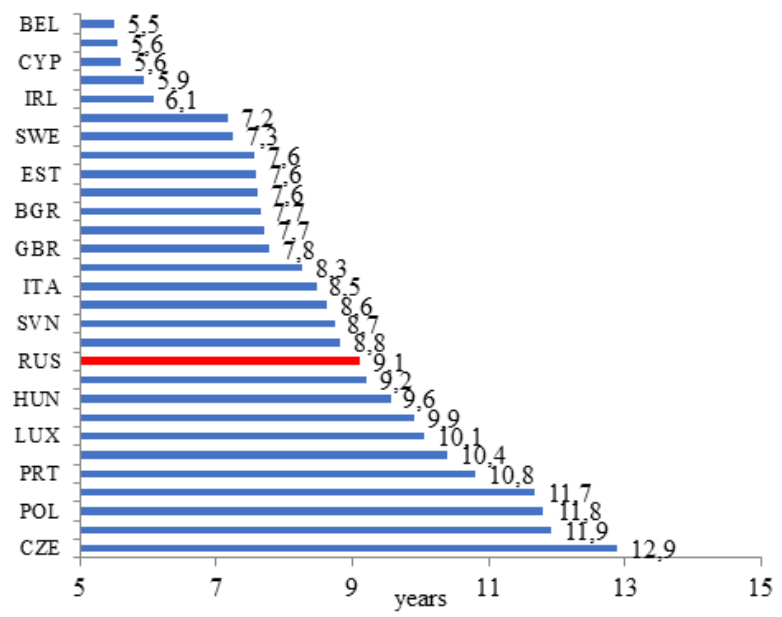

Fig. 6. Rating of the EU countries and Russia by the level of housing affordability coefficient in 2019 , years.

At the final stage, we will conduct a correlationregression analysis of the totality of the European Union countries, except for Russia. The exclusion from the considered group of the Russian Federation is due to low values, that is, this country is an "outlier" and will distort the prevailing patterns that have developed in Europe. Correlation coefficient values indicate no relationship between factors and variable $\mathrm{Z3}$. In turn, the variables $\mathrm{Z1}$ and $\mathrm{Z} 2$ are influenced by most independent variables. So, the rise in interest rates on mortgages (U6) will "scare off" potential loan consumers because of prices in the real estate market will go down. An increase in the ratio of mortgage to household income (U7) will force the population to make a choice in favor of renting housing, because of which the supply of housing will decline.

The analysis showed that the joint use of the entire set of independent variables within a single regression model is not possible (contradicts the methodology of econometric research).

One of the methods of dealing with multicollinearity is an approach called the method of sequential exclusion of factors.

Applying this procedure to the data at our disposal leads to two one-factor models:

$$
\begin{gathered}
\mathrm{Z1}^{\prime}=609,2375+1,9739 \times \mathrm{U} 4 \\
\mathrm{Z}^{\prime}{ }^{\prime}=1,0576+0,0008 \times \mathrm{U} 3
\end{gathered}
$$

A qualitative interpretation of the coefficients of the constructed econometric models is as follows:

- firstly, with an increase in the average monthly wage by 1 thousand US dollars, the price per sq. meters of housing in the city center will grow on average by 1973.9 thousand US dollars, while other factors remain unchanged. Thus, the rise in living standards provokes a rise in prices in the real estate market.

- secondly, an increase in the rent of an apartment in the city center by USD 1000 will lead to an increase in the provision of the population with housing by 0.8 
rooms per person. That is, the deterioration of the situation in the rental market (from the tenant's point of view) stimulates (provokes) a potential buyer to acquire real estate in ownership.

\section{Conclusion}

Summing up the study of the factors operating in the construction market and related industries (including the real estate market) of the EU countries, we can formulate several conclusions.

Firstly, Russia ranks first in terms of the share of GVA in the country's GDP, with a value of $6.8 \%$, on the one hand, this indicates a significant role of the industry in the country's economy, but on the other hand, about the difference in the structure of production in the Russian Federation and the EU (in the eurozone, a greater bias is placed on the service sector). It is worth noting that, despite the impressive share of construction, as well as high rates of commissioning of real estate, the provision of the population with housing in Russia is lagging European countries, its closest neighbors are ROU, HRV, POL.

Secondly, the positioning of Russia based on all variables included in the system of indicators, using the method of multidimensional scaling, showed that the country is not included in more than one cluster of European countries (it lies at a distance from the main cluster of countries). Thus, it can be stated that the Russian Federation lags the EU in terms of living standards of the population, as a result, prices on the housing market are low, since they are constrained by low per capita incomes.

Third, the correlation-regression analysis showed that the variable $\mathrm{Z} 3$, which to some extent characterizes the construction industry and its role in the country's economy, is not significantly influenced by any of the variables included in the system of indicators. The obtained dependences for variables $\mathrm{Z} 1$ and $\mathrm{Z} 2$ do not contradict the mechanics of the described processes and indicate the impact on the housing market (both the purchase of housing and rental housing) of the standard of living of the population.

Fourth, the assessment of Russia's position relative to the EU countries, based on a set of statistical methods, showed a lag in the development of the construction industry and significant differences observed in the housing market. As a result of the analysis, we can say with confidence that the potential for growth in construction and related subjects in the Russian Federation exists, it all depends on the standard of living of the population (the level of per capita income).

\section{References}

1. M. Ermilova, Y. Finogenova, The Impact of Macroeconomic Factors and Economic Cycles on the Cost of Housing, International Journal of Ecological Economics \& Statistics

2. T. Boyd, Property market analysis, The key to looking forward, PRRES [Electronic resource]
(2014)

Available

at: http://www.prres.net/papers/Boyd_Property_Mar ket Analysis.pdf

3. B. Zhu, M. Betzinger, S. Sebastian, Housing market stability, mortgage markets structure, and monetary policy: Evidence from the euro area, Journal of Housing Economics, 37, 1-21 (2017)

4. T.N. Kokotkina, Statistical analysis of the impact of human potential on the housing market of the Volga Federal District, Bulletin of the Mari State University, Series: Agricultural Sciences, Economic sciences, 1, 2 (2), 74-78 (2015)

5. L.V. Tatarinova, V.A. Plotnikova, Factors affecting mortgage lending in the Russian Federation, Business, Education, Right, 4 (45), 208-216 (2018)

6. D.M. Blackley, J.R. Follain, An econometric model of the metropolitan housing market, Journal of Housing Economics, 1 (2), 140-167 (1991)

7. P. Sunega, M. Lux, P. Zemčík, Housing Price Volatility and Econometrics, Critical housing analysis, 1 (2), 70-78

8. J. Halket, L. Nesheim, F. Oswald, The Housing Stock, Housing Prices, and User Costs: The Roles of Location, Structure, and Unobserved Quality, International Economic Review, 61 (4) (2020)

9. J.R. Follain, S.H. Giertz, Predicting House Price Bubbles and Busts with Econometric Models: What We've Learned, What We Still Don't Know, Lincoln Institute of Land Policy (2012)

10. R.J. Rodríguez, Quantitative analysis of commercial and residential real estate markets (an approach from cointegration and spatial econometrics) 